\title{
LETTER
}

\section{Invasive pulmonary and central nervous system aspergillosis following slops aspiration in a trauma patient}

\author{
Mao Zhang', Guang-Ju Zhou* ${ }^{1 *}$ Xuan-Ding Wang², Lian Wang', Jian-Xin Gan' and Shao-Wen Xu'
}

Cerebral aspergillosis is a rare complication of multiple trauma. In this report, we present a remarkable case of multiple lung and brain lesions caused by aspergillosis after a falling incident.

A 54-year-old male was admitted with multiple trauma (brain contusion, aspiration pneumonitis with pulmonary contusion, right humerus fracture and right scapular fracture) due to a 6-m fall and aspiration of slops. In view of aspiration pneumonitis (Figure 1, day 1), intravenous antibiotic treatment (tazocin, moxifloxacin hydrochloride and metronidazole) was started. Brain computerized tomography (CT) on day 12 indicated a focus of encephalomalacia in the left frontal lobe, which was thought to be the progress of brain contusion (Figure 1, day 12). On the same day, chest CT showed a pulmonary halo sign on the left upper lung (Figure 1, day 12), and voriconazole therapy was used because of high suspicion of invasive pulmonary fungal infection. Voriconazole treatment had to be stopped, however, due to severe rash 5 days later. Anti-fungus therapy was continued with caspofungin. On day 19, the brain CT showed signs of fungus infection (Figure 1, day 19). Twenty-two days after injury, the central venous catheter culture grew aspergillus species and established the diagnosis of invasive aspergillosis in this patient; liposomal amphotericin B was then also added to the patient's treatment. On day 34, enhanced CT imaging of the brain showed progression of multiple lesions of fungus infection (Figure 1, day 34). Unfortunately, the patient died 40 days after injury.

We have described invasive aspergillosis with a rapidly progressive and fatal pulmonary and cerebral course in a previously healthy man. Neuroaspergillosis is an

\footnotetext{
*Correspondence: zhoutom1978@hotmail.com

'Department of Emergency Medicine, Second Affiliated Hospital, Zhejiang

University, School of Medicine, Research Institute of Emergency Medicine,Zhejiang

University, No.88 Jiefang Road Hangzhou, 310009 China

Full list of author information is available at the end of the article
}

uncommon infection associated with an exceedingly high mortality. The diagnosis of neuroaspergillosis is difficult, often made at the terminal stage of disease or on autopsy [1]. Perhaps due to the greater penetration into the central nervous system (CNS), voriconazole treatment greatly improved clinical outcomes with a survival rate of $30 \%$ in high-risk patients [2,3]. According to the guidelines for treating invasive pulmonary aspergillosis, voriconazole is recommended for primary treatment [4]. Unfortunately, this patient was refractory to voriconazole because of severe rash, and then caspofungin was selected for salvage therapy. Owing to the large molecular mass, high protein binding and water solubility of caspofungin, its penetration into the CNS was limited [5]; this invasive pulmonary aspergillosis was then further complicated by dissemination to the CNS on day 19.

In conclusion, we report a rare trauma case accompanied with invasive pulmonary and CNS aspergillosis following slops aspiration. This case highlights the diagnostic challenge presented by invasive aspergillosis in non-neutropenic patients and underscores its poor prognosis.

\section{Abbreviations}

CNS, central nervous system; CT, computerized tomography.

\section{Competing interests}

The authors declare that they have no competing interests.

\section{Acknowledgements}

Written consent for publication was obtained from the patient's next-of-kin.

\section{Author details}

'Department of Emergency Medicine, Second Affiliated Hospital, Zhejiang University, School of Medicine, Research Institute of Emergency Medicine, Zhejiang University, No.88 Jiefang Road Hangzhou, 310009 China.

${ }^{2}$ Department of Respiratory Disease, Second Affiliated Hospital, Zhejiang University, School of Medicine, No.88 Jiefang Road Hangzhou, 310009 China.

Published: 24 September 2010

\section{References}

1. Brun S, Fekkar A, Busse A, Seilhean D, Lecsö M, Adler D, Prodanovic H, Mazier D, Datry A: Aspergillus flavus brain abscesses associated with hepatic amebiasis in a non-neutropenic man in Senegal. Am J Trop Med Hyg 2009, 81:583-586. 


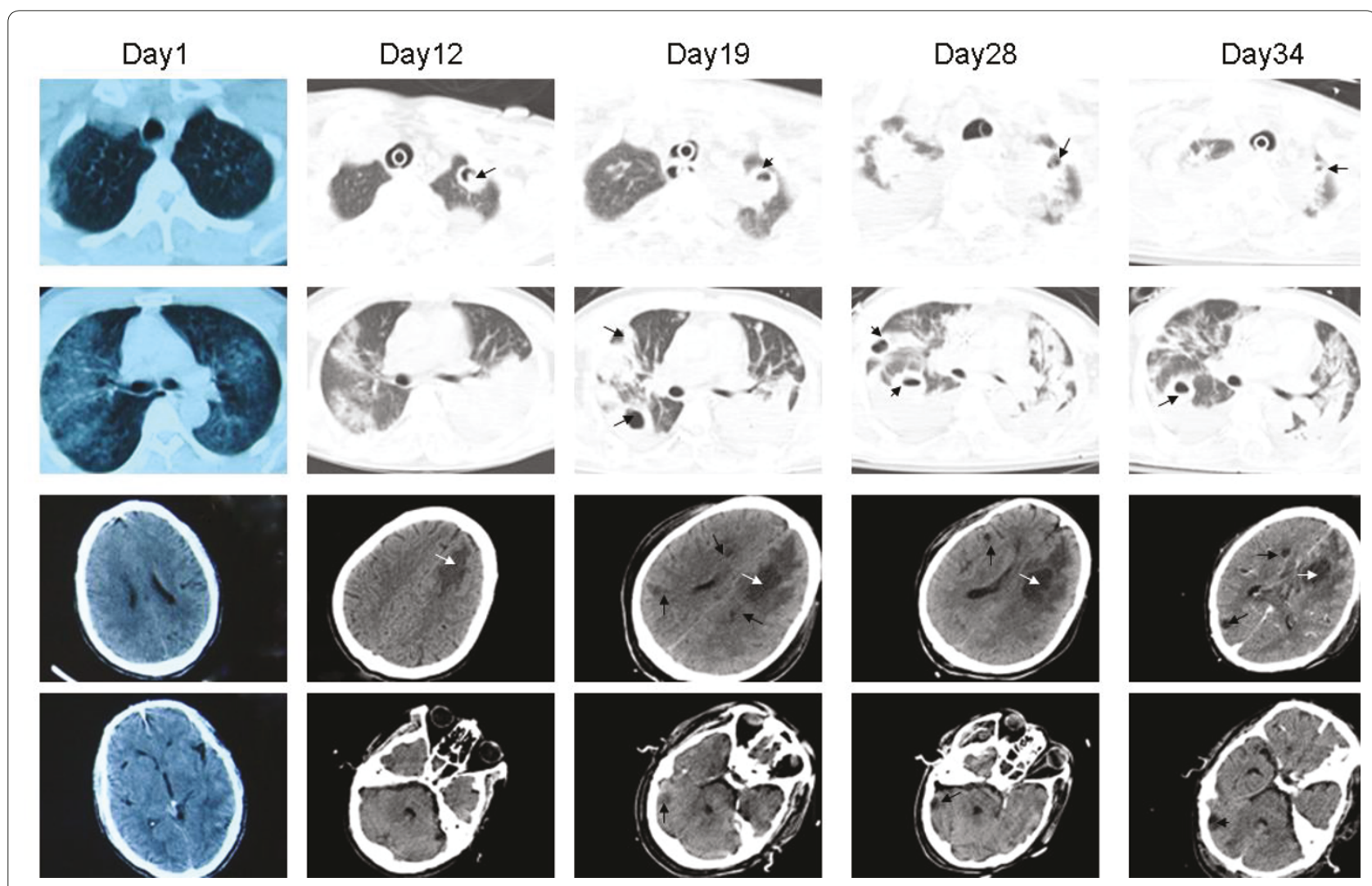

Figure 1. Chest and brain computerized tomography on days 1, 12, 19, 28, and 34 . Aspiration pneumonitis with pulmonary contusion was shown on day 1. Black arrows, multiple lesions of fungus infection in both the lung and the brain. White arrows, progression of encephalomalacia in the left frontal lobe.

2. Lin SJ, Schranz J, Teutsch SM: Aspergillosis case-fatality rate: systematic review of the literature. Clin Infect Dis 2001, 32:358-366.

3. Schwartz S, Ruhnke M, Ribaud P, Corey L, Driscoll T, Cornely OA, Schuler U, Lutsar I, Troke P, Thiel E: Improved outcome in central nervous system aspergillosis, using voriconazole treatment. Blood 2005, 106:2641-2645.

4. Walsh TJ, Anaissie EJ, Denning DW, Herbrecht R, Kontoyiannis DP, Marr KA, Morrison VA, Segal BH, Steinbach WJ, Stevens DA, van Burik JA, Wingard JR, Patterson TF; Infectious Diseases Society of America: Treatment of aspergillosis: clinical practice guidelines of the Infectious Diseases Society of America. Clin Infect Dis 2008, 46:327-360.
5. Park DW, Sohn JW, Cheong HJ, Kim WJ, Kim MJ, Kim JH, Shin C: Combination therapy of disseminated coccidioidomycosis with caspofungin and fluconazole. BMC Infect Dis 2006, 6:26.

doi:10.1186/cc9228

Cite this article as: Zhang M, et al:. Invasive pulmonary and central nervous system aspergillosis following slops aspiration in a trauma patient. Critical Care 2010, 14:442. 